\title{
BMPs oppose Math1 in cerebellar development and in medulloblastoma
}

\author{
Matthew R. Grimmer and William A. Weiss ${ }^{1}$ \\ Department of Neurology, Department of Pediatrics, and Department of Neurological Surgery, University of California at \\ San Francisco, San Francisco, California 94143, USA
}

Bone morphogenetic proteins (BMPs) are soluble effectors of differentiation and are central in orchestrating development of organs including the cerebellum. The transcription factor and BMP target Math1 (mouse atonal homolog 1) is a critical regulator of neuronal progenitors destined to form the cerebellar cortex. Signaling networks controlled by BMPs, Math1, and Sonic Hedgehog (Shh) together regulate the proliferation and differentiation of cerebellar progenitor cells. Defects in these pathways are also implicated in medulloblastoma, the most common pediatric brain tumor. In this issue of Genes \& Development, Zhao et al. (2008) perform an elegant set of experiments that clarify the role of BMPs and of Math1 in medulloblastoma. Destabilization of Math1 by treatment with BMP-2 or BMP-4 induced neuronal differentiation in cells from mouse models of Shh-driven medulloblastoma and reduced proliferation in established tumors in vivo. These studies provide important new insights into the vulnerabilities of medulloblastoma and present future therapeutic promise.

\section{A primer on cerebellar development}

The cerebellum is a posterior brain structure that coordinates numerous neurological functions including smooth movement. The two most common neurons in the adult cerebellum are Purkinje cells, which form a single cell layer, and smaller granule cells deep to the Purkinje layer. Cerebellar development shares a commonality with development of other brain structures in that a population of cells arises from a primitive ventricular neuroepithelium. Closure of the neural tube creates a ventricular zone of neural progenitor cells that extends along the entire fetal ventricular surface and contributes to most brain structures. In the hindbrain, the ventricular zone forms the inner aspect of the cerebellar anlage and gives rise to Purkinje neurons and to glia. The ventricular zone of the cerebellum is unique, however, in that it also contributes to the rhombic lip, a ridged structure at the posterior edge of the cerebellar anlage.

${ }^{1}$ Corresponding author.

E-MAIL weiss@cgl.ucsf.edu; FAX (415) 502-1694.

Article is online at http://www.genesdev.org/cgi/doi/10.1101/gad.1657808.
Although the ventricular zone is responsible for much of the early development of the cerebellum, granule cells - the most abundant neuronal subpopulation in the adult brain-arise in the rhombic lip. Granule neuron precursors (GNPs) generated in the rhombic lip undergo massive clonal expansion and migration over the dorsal periphery of the cerebellar anlage to populate the external layers of cerebellum (Hatten and Heintz 1995). This process forms a secondary germinal zone called the external granule layer (EGL). In a continuous process completed by postnatal day 21 (P21) in mice, GNPs migrate from the EGL and through the Purkinje cell layer (Fig. 1). At this point, migrating GNPs form an initial T-shaped process on the brain surface, the body of which trails behind them as they migrate inward, exit the cell cycle, and extend additional processes to populate the internal granule layer (IGL) (Choi et al. 2005). The expansion of GNPs is orchestrated principally by Shh, a highly conserved morphogen that directs development in different organs in a paracrine fashion.

\section{Proliferation of GNPs is regulated by Shh and Math1}

Initially discovered in insects, hedgehog is a secreted mitogen that regulates segment polarity in the Drosophila embryo. Three mammalian homologs exist, of which Shh is critical to the formation of numerous structures in the developing nervous system. In the cerebellum, Shh regulates the generation of granule cells. Shh is secreted by Purkinje cells deep to the EGL and acts on GNPs to stimulate their proliferation (Dahmane and Ruiz i Altaba 1999; Wallace 1999; Wechsler-Reya and Scott 1999). Shh binds its receptor, Patched1 (Ptch), relieving inhibition of the seven-pass transmembrane protein, Smoothened (Smo). In the presence of Shh, Smo activates a signaling cascade directed principally through downstream Gli transcription factors. The characterization of recombinant Shh and of Ptch mutant mice has contributed to our understanding of Shh signaling and its role in development. Treatment of GNPs with Shh in vitro prevents their differentiation and maintains proliferation (Wechsler-Reya and Scott 1999; Kenney et al. 2003). Conversely, blockade of Shh signaling in vivo disrupts normal cerebellar development, principally through blocking proliferation of GNPs in the EGL (Wallace 1999; Wechsler-Reya and Scott 1999). 


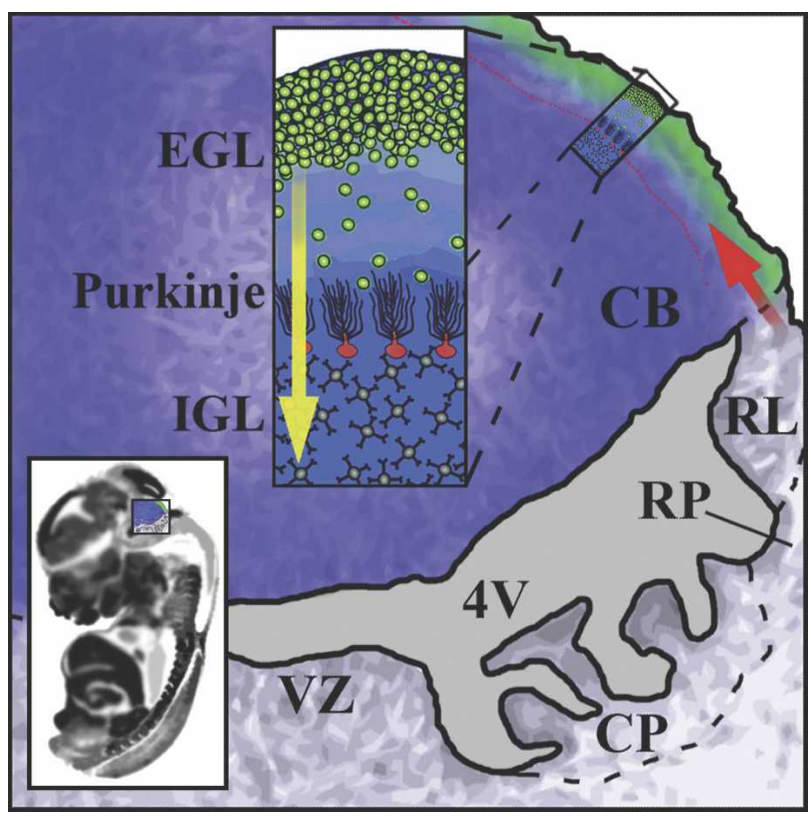

Figure 1. Schematic of mouse cerebellar development. Math1expressing GNPs arise in the rhombic lip (RL), a structure at the junction of the roof plate (RP) and cerebellar anlage (CB). Shhdriven clonal expansion of GNPs (red arrow) forms the EGL, from which GNPs then migrate through the Purkinje layer (yellow arrow) to become mature granule neurons in the IGL. The ventricular zone (VZ), a thin layer lining the fourth ventricle $(4 \mathrm{~V})$ and inner region of the cerebellar anlage, produces Purkinje neurons, which secrete Shh. Choroid plexus (CP) is shown for orientation. Adapted by permission from Macmillan Publishers Ltd: Nature (Millonig et al. 2000), (C) 2000; and adapted with permission from Rupp et al. (2006).

Math1 is a basic helix-loop-helix (bHLH) transcription factor expressed in the dorsal neural tube and the rhombic lip. Math1 is the earliest marker of developing granular neurons in the EGL that subsequently migrate over the dorsal surface of the cerebellar anlage (Machold and Fishell 2005; Wang et al. 2005). The developing cerebella of mice carrying a Math1-GFP transgene exhibit fluorescence in the rhombic lip as early as embryonic day 9.75 (E9.75) and in the EGL at P0. After P21, the EGL no longer exists and Math1 is not expressed (Ben-Arie et al. 1997; Lumpkin et al. 2003).

Initial specification of GNPs in the rhombic lip occurs independently of Math1; viable GNPs were successfully produced in the rhombic lip of Math1-null mice, although the rhombic lip was smaller than in control mice (Gazit et al. 2004). However, other loss-of-function studies highlighted a dependence on Math1 for proliferation of cells migrating from the rhombic lip to populate the EGL and for formation of mature granule cells in the cerebellum. Math1-null mice have no EGL at E18.5, a time point when normal EGL is several cells thick (BenArie et al. 1997). Induction of proliferation by Math1 likely results from activation of downstream gene targets. Tissue-specific bHLH transcription factors heterodimerize with ubiquitously expressed bHLH proteins.
Math1 forms such complexes with E47, which then activates transcription of E-box-containing target genes, including those implicated in proliferation (Castro et al. 2006). Together, these findings establish a requirement for Math1 in proliferation of GNPs.

The specific role played by Math1 in driving both proliferation and differentiation becomes more complicated after GNPs populate the EGL, where Shh signals also regulate proliferation. Overexpression of Math1 leads to early expression of differentiated markers, such as the neurogenesis factor NeuroD, suggesting that Math1 drives proliferation and concurrently initiates differentiation in GNPs. Importantly, while initial differentiation of GNPs to mature neurons requires Math1 (Gazit et al. 2004), overexpression of Math1 blocks the terminal differentiation of cells in the mature IGL (Helms et al. 2001). These results suggest that fine-tuning of Math1 levels is critical to normal cerebellar development.

How can the same transcription factor initiate both proliferative and differentiative programs? Levels of Math1 are tightly regulated during cerebellar development and blockade or decreased expression of Math1 appears to promote differentiation of GNPs. Math1 binds to its own promoter, with high levels of Math1 blocking further expression (Helms et al. 2001; Gazit et al. 2004). Gazit et al. (2004) knocked LacZ (the structural gene for $\beta$-gal) into the Math1 locus and monitored $\beta$-gal activity in mice heterozygous or homozygous for this knock-in. Heterozygous mice retain a wild-type allele of Math1 and showed decreased $\beta$-gal activity after $6 \mathrm{~d}$. In contrast, mice homozygous for this knock-in do not express Math 1 and showed sustained $\beta$-gal activity beyond $6 \mathrm{~d}$. Parallel signaling pathways may also serve to antagonize the Math1 signal. The Notch pathway is a critical component of GNP maturation and is a well-established contributor to cerebellar development. In cultured GNPs, Notch signaling inhibits the transcription of Math1 target genes (Gazit et al. 2004), suggesting that Notch and Math1 may coordinately control both neurogenesis and differentiation.

\section{BMPs interact with Math1 to coordinate cell fate}

The BMPs family of proteins regulates cell cycle exit, migration, and differentiation of GNPs during early cerebellar development. BMPs are pleiotropic members of the transforming grow th factor receptor $\beta$ (TGF- $\beta$ ) superfamily. There are $>20$ BMPs, including BMP2-4, homologs of the Drosophila Decaptenaplegic ( $D p p)$ gene, and BMP5-8, homologs of the Drospophila $60 \mathrm{~A}$ gene. $\mathrm{BMPs}$ have been extensively characterized in limb patterning and as bone morphogens. Although comparably less is known about how specific BMPs contribute to cerebellar development, an emerging literature establishes a role for BMPs in the specification and differentiation of cells derived from the rhombic lip.

Distinct BMPs are expressed in overlapping regions of the developing cerebellum and interact with Math1 to regulate the stepwise specification and differentiation of GNPs (Lee et al. 2000). The 60A family members, BMP6 
and BMP7, are expressed adjacent to the cerebellar anlage in the murine roof plate, a distinct cell layer implicated in proliferation and migration of GNPs (Chizhikov et al. 2006). Treatment of cultured cerebellar progenitors with BMP6 or BMP7 induces expression of GNP markers including Math1 (Alder et al. 1999). Consistent with these observations in vitro, BMP7 was sufficient to induce expression of Math1 in GNPs in the rhombic lip (Krizhanovsky and Ben-Arie 2006). Perhaps most impressively, BMP treatment also promoted granular neurogenesis from ventral neural tube progenitors (a population of cells not normally destined to become neurons), demonstrating the potency of BMPs as inducers of neuronal specification.

Continued expression of BMP7 antagonizes differentiation of GNPs, preferentially maintaining GNPs in a Math1-expressing, proliferative state. Differentiation of GNPs into IGL neurons thus requires blockade or downregulation of BMP7, achieved through Math1-driven expression of the BMP7 antagonist Nbl1. Nbll relieves the effects of BMP7 and allows further differentiation toward mature granule neurons (Krizhanovsky and Ben-Arie 2006). This temporal regulation of BMP activity is accompanied by exquisite regulation of BMP signaling. Specific levels of BMPs are clearly necessary to specify proliferative precursor species and to orchestrate the proper timing for their switch to a program of differentiation. Loss of function studies in BMP Type I receptors leads to blockade of signal transduction from all BMPs, substantial reduction in levels of Math1, and concomitant cerebellar disorganization with marked defects in both Purkinje cells and granule cells (Qin et al. 2006). Aberrant BMP signaling through expression of a constitutively activate BMP Type I receptor in chick embryos also produced underdeveloped, disorganized cerebella. Ectopic foci of granule cells were observed, presumably from aberrant migration into the white matter (Ming et al. 2002).

\section{Smad proteins transduce BMP signals to the nucleus}

BMPs are synthesized as propeptides that are cleaved, leaving a C-terminal mature protein. BMPs bind distinct heterodimeric combinations of Type I or Type II serinethreonine kinase receptors. Activation of Type II receptors leads to transphosphorylation of Type I receptors, which subsequently phosphorylate effector proteins Smad1, Smad5, and Smad8. The Smads are a conserved protein family of transcription factors that relay signals from TGF $\beta$ family members. While the role of the BMP signaling is complex and changes through development, Smad1, Smad5, and Smad8 are the only known functional effectors of BMP signaling. Activation of Smad1, Smad5, and Smad8 proteins, known as receptor Smads, enables interaction with Smad4. The resulting heterodimers then translocate to the nucleus to activate a broad array of target genes (Fuentealba et al. 2007).

Whereas BMP7 and other $60 \mathrm{~A}$ family members are expressed near the roof plate, $D p p$ family members BMP-2 and BMP-4 are expressed in GNPs and mature granule neurons in the IGL. Treatment of GNPs with BMP-2 and BMP-4 represses proliferation in the developing cerebellum (Rios et al. 2004). To probe the role of BMPs and Smads during cerebellar development, Angley et al. (2003) studied GNPs harvested at postnatal time points. Western blots showed transient elevation of both Smad1 and BMP-4 at P7-P15, while BMP-2 levels remained relatively constant. Cultured GNPs treated with BMP-4 showed translocation of Smad1 to the nucleus, associated with a differentiated morphology and with expression of differentiated markers. Treatment using other TGF $\beta$ family members /which do not signal through Smad1) did not lead to comparable changes, suggesting that Smad1 was required for differentiation of GNPs. Furthermore, antisense targeting of Smadl also blocked differentiation, again supporting Smad 1 as the effector of BMP-4 treatment. Smad5 appeared to be important for BMP-2 signals (Angley et al. 2003). The ability of BMP-2 and BMP-4 to down-regulate highly proliferative GNPs is thus critical to the ability for GNPs to exit the cell cycle and to differentiate during the course of migrating through the Purkinje layer (Rios et al. 2004).

Given that BMP-2 and BMP-4 can ablate proliferative signals from Shh and that these BMPs are expressed in GNPs, what signals permit proliferation of GNPs in the setting of BMP-2 and BMP-4? The Id family of transcriptional repressors is induced in response to Smads, and can, in turn, activate proliferation and inhibit differentiation (Lopez-Rovira et al. 2002). Id2 is expressed in rat EGL at P5, whereas Id1, Id2, and Id3 are expressed in IGL at the same time point. Id2 blocks differentiation of GNPs in part through preventing DNA binding by NeuroD-a requisite driver of granule cell differentiation (Korchynskyi and ten Dijke 2002; Lasorella et al. 2006).

As Smads are the sole effectors of BMP signal transduction, differential phosphorylation of Smads contributes to the complex temporal and spatial control of GNP proliferation and differentiation in the setting of BMP-2 and BMP-4 signaling. Activation of BMP-2 and BMP-4 leads to C-terminal phosphorylation of Smad1, translocating Smad1 to the nucleus where it regulates BMP target genes. The resulting transcriptional program is limited by degradation of phospho-Smad1, a process that is tightly coordinated through growth-promoting pathways. An initial, priming phosphorylation of Smad1 from MAP kinase allows a second phosphorylation from glycogen synthase kinase $3 \beta$ (GSK-3 $\beta$ ) four residues away (Pera et al. 2003; Fuentealba et al. 2007). GSK-3 $\beta$ lies at the intersection of several prominent signaling pathways instrumental in determining cell fate. GSK-3 $\beta$ driven phosphorylation of Smad1 drives polyubiquitination and subsequent degradation, abrogating its ability to carry out BMP transcriptional programs (Pera et al. 2003; Fuentealba et al. 2007).

\section{BMPs, Math1, and Shh in medulloblastoma}

The observations that BMPs, Math1, and Shh play essential roles in the proliferation of EGL neurons raises questions as to whether aberrant signaling through BMPs or 
Math1 contribute to cancer. Medulloblastoma, the most common brain tumor of childhood, typically arises in the cerebellum and is composed of primitive embryonal cells that retain the ability to differentiate into glia and neurons. Clues to the genetic basis of medulloblastoma were uncovered by the study of a familial medullobastoma predisposition syndrome, Gorlin's syndrome, which is caused by somatic mutation of the PTCH gene, a negative regulator of Shh signaling (Johnson et al. 1996). Although medulloblastoma is only rarely observed in patients with Gorlin's syndrome, activation of Shh signaling in sporadic tumors has revealed that $20 \%-$ $30 \%$ of medulloblastomas have inappropriate activation of Shh signaling (Zurawel et al. 2000; Pomeroy et al. 2002). Math1 is also up-regulated in medulloblastoma tumors. Activation of Shh signaling and expression of Math1 in this malignancy therefore specify that subset of tumors likely to have arisen from the EGL (Lee et al. 2003; Thompson et al. 2006).

The Mycn proto-oncogene is a primary executor of Shh signaling. Levels of murine N-Myc increase in response to Shh signaling, both through transcriptional activation and through post-transcriptional stabilization. While details linking Shh to transcription and stabilization of $\mathrm{N}$ Myc remain incompletely understood, Shh stabilization of N-Myc protein likely proceeds through inhibition of GSK-3 $\beta$, which phosphorylates and targets degradation of N-Myc in the proteasome in a manner similar to that described for Smad1 above (Sjostrom et al. 2005). Amplification of human MYCN or family member $c-m y c$ is observed in $5 \%-8 \%$ of medulloblastoma cases. Although $\mathrm{N}-\mathrm{Myc}$ is normally undetectable in postnatal cerebellum, aberrant expression of Mycn (human) in the absence of amplification is observed in the vast majority of human medulloblastomas, suggesting a contribution to pathogenesis (Pomeroy et al. 2002; Eberhart et al. 2004; Gajjar et al. 2004). Brain-specific deletion of $N-M y c$ disrupted expansion of GNPs and blocked murine medulloblastoma driven by aberrant Shh signaling (Knoepfler et al. 2002; Hatton et al. 2006), whereas overexpression of N-Myc drives proliferation of GNPs in the absence of Shh signals (Kenney et al. 2003). Thus, misexpression of $\mathrm{N}-$ Myc likely contributes to the pathogenesis of both Shh-driven and Shh-independent medulloblastoma tumors.

Aberrant signaling through Shh is the basis for essentially all genetically engineered mouse models of medulloblastoma, supporting the potency of this oncogenic pathway. However, it is again worth noting that most existing mouse models for this disease represent only the $\sim 20 \%-30 \%$ of tumors defined by aberrant Shh signaling. The majority of these Shh-driven mouse tumors also require a second genetically engineered mutation, typically loss of p53-which is uncommon in human tumors driven by Shh-in order to increase penetrance beyond $50 \%$ (Wetmore et al. 2001). The first, and among the most productive, model of Shh-driven medulloblastoma was generated by heterozygous deletion of mouse Ptch. Inactivation of Ptch allows unabated activation of Smo, resulting in pathway activation (Wetmore et al. 2000).
The use of Ptch mutant mouse models of the disease, in tandem with Shh pathway inhibitors, has been invaluable to the investigation of Shh signaling in medulloblastoma. Cyclopamine, a plant steroidal alkaloid, shows affinity for Smo and inhibits cellular responses to Shh signaling. Cyclopamine abrogates Shh signals in much the same way as Ptch, by binding Smo and converting active Smo to its inactive conformation (Taipale et al. 2000; Frank-Kamenetsky et al. 2002). Although no other targets for cyclopamine are presently known, the anti-proliferative effects induced by this drug in many cases require dosing above that needed to block Shh signaling, raising questions regarding specificity. In Ptch mutant murine medulloblastoma tumors, cyclopamine and its derivatives are highly effective at blocking proliferation, inducing cell death, and even curing mice (Berman et al. 2002; Romer et al. 2004). A mouse model utilizing a constitutively active allele of Smo also resulted in medulloblastomas that responded to cyclopamine (Hallahan et al. 2004). In cases where Shh is activated downstream from Smo, inhibitors of Smo are likely to have limited activity (Thompson et al. 2006). Activation of Gli proteins is the final step in Shh signaling. Recently developed small-molecule Gli inhibitors have shown promise preclinically in tumors driven by signals downstream from Smo (Lauth et al. 2007).

Retinoids can also block proliferation and induce apoptosis in medulloblastoma cells, likely through modulating the activity of BMP proteins. Spiller et al. (2007) treated Smo-driven medulloblastoma tumors with retinoids, demonstrating apoptosis in vivo. Hallahan et al. (2003) demonstrated that BMP-2 is a primary target of retinoids in vitro, as retinoid-induced apoptosis was blocked by addition of the BMP-2 antagonist Noggin.

\section{Can BMPs be used therapeutically in medulloblastoma?}

In this issue of Genes \& Development, Zhao et al. (2008) investigate the effects of BMP-2 and BMP-4 on Shhdriven medulloblastoma. Their initial studies confirm that treatment with BMP-2 or BMP-4 could block proliferation in GNPs derived from normal murine P7 cerebella. GNPs treated with Shh, and either recombinant BMP-2 or BMP-4 proteins showed arrest at G1 and incorporated less BrdU than controls treated with Shh in the absence of BMPs. Similar blockade of proliferation cells was observed by withdrawal of Shh or by treatment with cyclopamine. These data suggest that treatment of GNPs with BMP-2 or BMP-4 could abrogate mitogenic signals driven by Shh.

Zhao et al. (2008) go on to confirm the anti-proliferative effects of BMP treatment in tumor cells derived from mouse models of medulloblastomas driven by aberrant Shh signaling. These mice were homozygous for deletion of the cyclin-dependent kinase (cdk) inhibitor Ink $4 c$ in the setting of either heterozygous deletion of Ptch or neural-specific deletion of $p 53\left(\operatorname{Ink} 4 c^{-/-}, \mathrm{Ptch}^{+/-}\right.$or Ink $4 c^{-/-}, p 53^{F l-}$, Nestin-cre). In addition to undergoing G1 arrest, these cells showed differentiation in response 
to treatment with recombinant BMP-4, evidenced by extension of neuronal processes and concurrent expression of neuronal markers, Tag1 and Tuj1.

Examination of signaling in Shh-treated GNPs and in tumor cells verified that BMP-2 and BMP-4 led to activation of Smad1 and expression of downstream Id proteins. Tumor cells treated with BMP-4 showed reduced levels of Math1 protein, occurring rapidly (24 h) in comparison with cyclopamine $(72 \mathrm{~h})$. Conversely, cyclopamine was able to reduce levels of N-Myc more rapidly (12 h) than BMP-4 (72 h). Down-regulation of Math1 was required for cell cycle exit in response to BMP treatment and correlated with reduction in cyclin D1 and Cdk2, regulators of cell cycle exit. Importantly, the details of cell cycle arrest differed using BMPs and cyclopamine, with combination therapy acting additively to block proliferation.

Mechanistically, BMP-4 blocked Math1 through a post-transcriptional mechanism in GNPs, as Math1 protein was absent in BMP-treated cells by $18 \mathrm{~h}$, with negligible changes in levels of Math1 mRNA. Using cycloheximide pulse-chase and proteasome inhibitor experiments, Zhao et al. (2008) showed that BMP-4 treatment drives degradation of Math1 protein in the proteasome. In 293 T cells, Math1 was demonstrably stabilized by coexpression of its transcriptional partner E47. In contrast, coexpression of Id2 lead to rapid degradation, suggesting that BMP treatment and subsequent expression of $\mathrm{Id} 2$ may compete with Math1 in binding E47, thereby contributing to degradation of Math1.

To interrogate the effects of BMP-4 in establishment of medulloblastoma in vivo, Zhao et al. (2008) isolated tumor cells from both models, and infected these with vectors expressing green fluorescent protein (GFP), either alone or in the presence of BMP-4. After transduction, cells were allografted subcutaneously into the flanks of immunodeficient mice, allowed to grow for 2-4 wk, and then harvested. Cells expressing BMP-4 and GFP were quite rare in comparison with cells only expressing GFP, suggesting that expression of BMP-4 was inhibiting proliferation or viability. Perhaps most interestingly, tumor cells pretreated with BMP-4 failed to allograft, suggesting BMP-4 as a potent anti-tumor agent.

To investigate the role of Math1 in tumor growth, Zhao et al. (2008) transduced the same GFP vectorsalone or in combination with Math1-into cells derived from $P t c h 1^{+/}$, Ink $4 c^{-/-}$mice. The abundance of Math1overexpressing tumor cells harvested from allografts of cells expressing Math1 and GFP suggests that Math1 promoted the proliferation of tumor cells in vivo. Additionally, overexpression of Math1 made tumor cells resistant to proliferation block in response to BMP-4, arguing that the efficacy of BMP-4 treatment proceeds through reduction in Math1 protein levels.

\section{Future directions}

In these manipulations of normal GNPs and GNP-like medulloblastoma cells, Zhao et al. (2008) provide new data linking BMPs to destabilization of Math1 protein, providing mechanistic insights into the anti-proliferative effects of BMP treatment and suggesting a role for BMPs in the therapy of medulloblastoma. Significant hurdles remain, however. In contrast to an earlier report linking BMP signaling to retinoid-induced apoptosis of human medulloblastoma cell lines (Hallahan et al. 2003), BMP treatment of murine medulloblastoma tumors resulted in proliferative arrest rather than cell death. Another earlier study revealed that BMP-2 inhibited apoptosis in a human medulloblastoma cell line (Iantosca et al. 1999). Future studies elucidating pertinent mechanisms of BMP signaling to proliferation and cell survival may help to explain these discrepancies. Recently, Alvarez-Rodriguez et al. (2007) showed that BMP-2 treatment antagonizes the proliferative effects of Shh in two distinct steps in GNPs. The first step promotes cell cycle arrest by down-regulating N-Myc and the second activates genes that drive differentiation.

Another challenge lies in delivery-BMPs are large proteins and cannot be readily delivered to patients. Small molecule approaches for this malignancy may be more straightforward, but small molecule inhibitors of Smo to date have had limited testing in patients. The first generation of these agents delivered topically to patients with Shh-driven skin cancers showed little blockade of Shh signaling, attributed to poor penetration into the skin. Enrollment in this Phase 1 trial was, therefore, stopped. In addition, medulloblastoma is a tumor of childhood, raising issues as to the impact of BMP agonists and Smo antagonists on development of normal brain structures. Finally, activation of Shh signaling is observed in a minority of medulloblastomas. The vast majority of these tumors-including the most aggressive large cell or anaplastic subset-is driven by as-yet poorly defined signaling pathways that may be independent of Shh. An understanding of genetic contributions to the majority of medulloblastomas and the ability to translate our knowledge of BMP and Shh signaling into clinical therapeutics represent important challenges for the future.

\section{Acknowledgments}

We thank Charles Eberhart, Joseph Gleeson, and Fredrik Johansson Swartling for critical review of the manuscript. We acknowledge support from the National Institutes of Health; the Wallace H. Coulter, Katie Dougherty, Pediatric Brain Tumor and Samuel G. Waxman Foundations; and the Burroughs Wellcome and Thrasher Research Funds.

\section{References}

Alder, J., Lee, K.J., Jessell, T.M., and Hatten, M.E. 1999. Generation of cerebellar granule neurons in vivo by transplantation of BMP-treated neural progenitor cells. Nat. Neurosci. 2: 535-540.

Alvarez-Rodriguez, R., Barzi, M., Berenguer, J., and Pons, S. 2007. Bone morphogenetic protein 2 opposes Shh-mediated proliferation in cerebellar granule cells through a TIEG-1based regulation of Nmyc. J. Biol. Chem. 282: 37170-37180. 
Angley, C., Kumar, M., Dinsio, K.J., Hall, A.K., and Siegel, R.E. 2003. Signaling by bone morphogenetic proteins and Smad1 modulates the postnatal differentiation of cerebellar cells. $J$. Neurosci. 23: 260-268.

Ben-Arie, N., Bellen, H.J., Armstrong, D.L., McCall, A.E., Gordadze, P.R., Guo, Q., Matzuk, M.M., and Zoghbi, H.Y. 1997. Math1 is essential for genesis of cerebellar granule neurons. Nature 390: 169-172.

Berman, D.M., Karhadkar, S.S., Hallahan, A.R., Pritchard, J.I., Eberhart, C.G., Watkins, D.N., Chen, J.K., Cooper, M.K., Taipale, J., Olson, J.M., et al. 2002. Medulloblastoma growth inhibition by hedgehog pathway blockade. Science 297: 1559-1561.

Castro, D.S., Skowronska-Krawczyk, D., Armant, O., Donaldson, I.J., Parras, C., Hunt, C., Critchley, J.A., Nguyen, L., Gossler, A., Gottgens, B., et al. 2006. Proneural bHLH and Brn proteins coregulate a neurogenic program through cooperative binding to a conserved DNA motif. Dev. Cell 11: 831-844.

Chizhikov, V.V., Lindgren, A.G., Currle, D.S., Rose, M.F., Monuki, E.S., and Millen, K.J. 2006. The roof plate regulates cerebellar cell-type specification and proliferation. Development 133: 2793-2804.

Choi, Y., Borghesani, P.R., Chan, J.A., and Segal, R.A. 2005. Migration from a mitogenic niche promotes cell-cycle exit. J. Neurosci. 25: 10437-10445.

Dahmane, N. and Ruiz i Altaba, A. 1999. Sonic hedgehog regulates the growth and patterning of the cerebellum. Development 126: 3089-3100.

Eberhart, C.G., Kratz, J., Wang, Y., Summers, K., Stearns, D., Cohen, K., Dang, C.V., and Burger, P.C. 2004. Histopathological and molecular prognostic markers in medulloblastoma: c-myc, N-myc, TrkC, and anaplasia. J. Neuropathol. Exp. Neurol. 63: 441-449.

Frank-Kamenetsky, M., Zhang, X.M., Bottega, S., Guicherit, O., Wichterle, H., Dudek, H., Bumcrot, D., Wang, F.Y., Jones, S., Shulok, J., et al. 2002. Small-molecule modulators of Hedgehog signaling: Identification and characterization of Smoothened agonists and antagonists. J. Biol. 1: 10. doi: 10.1186/ 1475-4924-1-10.

Fuentealba, L.C., Eivers, E., Ikeda, A., Hurtado, C., Kuroda, H., Pera, E.M., and De Robertis, E.M. 2007. Integrating patterning signals: Wnt/GSK3 regulates the duration of the BMP/ Smad1 signal. Cell 131: 980-993.

Gajjar, A., Hernan, R., Kocak, M., Fuller, C., Lee, Y., McKinnon, P.J., Wallace, D., Lau, C., Chintagumpala, M., Ashley, D.M., et al. 2004. Clinical, histopathologic, and molecular markers of prognosis: Toward a new disease risk stratification system for medulloblastoma. J. Clin. Oncol. 22: 984-993.

Gazit, R., Krizhanovsky, V., and Ben-Arie, N. 2004. Math1 controls cerebellar granule cell differentiation by regulating multiple components of the Notch signaling pathway. Development 131: 903-913.

Hallahan, A.R., Pritchard, J.I., Chandraratna, R.A., Ellenbogen, R.G., Geyer, J.R., Overland, R.P., Strand, A.D., Tapscott, S.J., and Olson, J.M. 2003. BMP-2 mediates retinoid-induced apoptosis in medulloblastoma cells through a paracrine effect. Nat. Med. 9: 1033-1038.

Hallahan, A.R., Pritchard, J.I., Hansen, S., Benson, M., Stoeck, J., Hatton, B.A., Russell, T.L., Ellenbogen, R.G., Bernstein, I.D., Beachy, P.A., et al. 2004. The SmoAl mouse model reveals that notch signaling is critical for the growth and survival of sonic hedgehog-induced medulloblastomas. Cancer Res. 64: 7794-7800.

Hatten, M.E. and Heintz, N. 1995. Mechanisms of neural patterning and specification in the developing cerebellum.
Annu. Rev. Neurosci. 18: 385-408.

Hatton, B.A., Knoepfler, P.S., Kenney, A.M., Rowitch, D.H., de Alboran, I.M., Olson, J.M., and Eisenman, R.N. 2006. N-myc is an essential downstream effector of Shh signaling during both normal and neoplastic cerebellar growth. Cancer Res. 66: $8655-8661$.

Helms, A.W., Gowan, K., Abney, A., Savage, T., and Johnson, J.E. 2001. Overexpression of MATH1 disrupts the coordination of neural differentiation in cerebellum development. Mol. Cell. Neurosci. 17: 671-682.

Iantosca, M.R., McPherson, C.E., Ho, S.Y., and Maxwell, G.D. 1999. Bone morphogenetic proteins-2 and -4 attenuate apoptosis in a cerebellar primitive neuroectodermal tumor cell line. J. Neurosci. Res. 56: 248-258.

Johnson, R.L., Rothman, A.L., Xie, J., Goodrich, L.V., Bare, J.W., Bonifas, J.M., Quinn, A.G., Myers, R.M., Cox, D.R., Epstein Jr., E.H., et al. 1996. Human homolog of patched, a candidate gene for the basal cell nevus syndrome. Science 272: 16681671.

Kenney, A.M., Cole, M.D., and Rowitch, D.H. 2003. Nmyc upregulation by sonic hedgehog signaling promotes proliferation in developing cerebellar granule neuron precursors. Development 130: 15-28.

Knoepfler, P.S., Cheng, P.F., and Eisenman, R.N. 2002. N-myc is essential during neurogenesis for the rapid expansion of progenitor cell populations and the inhibition of neuronal differentiation. Genes \& Dev. 16: 2699-2712.

Korchynskyi, O. and ten Dijke, P. 2002. Identification and functional characterization of distinct critically important bone morphogenetic protein-specific response elements in the Id1 promoter. J. Biol. Chem. 277: 4883-4891.

Krizhanovsky, V. and Ben-Arie, N. 2006. A novel role for the choroid plexus in BMP-mediated inhibition of differentiation of cerebellar neural progenitors. Mech. Dev. 123: 67-75.

Lasorella, A., Stegmuller, J., Guardavaccaro, D., Liu, G., Carro, M.S., Rothschild, G., de la Torre-Ubieta, L., Pagano, M., Bonni, A., and Iavarone, A. 2006. Degradation of Id2 by the anaphase-promoting complex couples cell cycle exit and axonal growth. Nature 442: 471-474.

Lauth, M., Bergstrom, A., Shimokawa, T., and Toftgard, R. 2007. Inhibition of GLI-mediated transcription and tumor cell growth by small-molecule antagonists. Proc. Natl. Acad. Sci. 104: 8455-8460.

Lee, K.J., Dietrich, P., and Jessell, T.M. 2000. Genetic ablation reveals that the roof plate is essential for dorsal interneuron specification. Nature 403: 734-740.

Lee, Y., Miller, H.L., Jensen, P., Hernan, R., Connelly, M., Wetmore, C., Zindy, F., Roussel, M.F., Curran, T., Gilbertson, R.J., et al. 2003. A molecular fingerprint for medulloblastoma. Cancer Res. 63: 5428-5437.

Lopez-Rovira, T., Chalaux, E., Massague, J., Rosa, J.L., and Ventura, F. 2002. Direct binding of Smad1 and Smad4 to two distinct motifs mediates bone morphogenetic protein-specific transcriptional activation of Idl gene. J. Biol. Chem. 277: 3176-3185.

Lumpkin, E.A., Collisson, T., Parab, P., Omer-Abdalla, A., Haeberle, H., Chen, P., Doetzlhofer, A., White, P., Groves, A., Segil, N., et al. 2003. Math1-driven GFP expression in the developing nervous system of transgenic mice. Brain Res. Gene Expr. Patterns 3: 389-395.

Machold, R. and Fishell, G. 2005. Math1 is expressed in temporally discrete pools of cerebellar rhombic-lip neural progenitors. Neuron 48: 17-24.

Millonig, J.H., Millen, K.J., and Hatten, M.E. 2000. The mouse Dreher gene Lmxla controls formation of the roof plate in the vertebrate CNS. Nature 403: 764-769. 
Ming, J.E., Elkan, M., Tang, K., and Golden, J.A. 2002. Type I bone morphogenetic protein receptors are expressed on cerebellar granular neurons and a constitutively active form of the type IA receptor induces cerebellar abnormalities. Neuroscience 114: 849-857.

Pera, E.M., Ikeda, A., Eivers, E., and De Robertis, E.M. 2003. Integration of IGF, FGF, and anti-BMP signals via Smad1 phosphorylation in neural induction. Genes \& Dev. 17: 3023-3028.

Pomeroy, S.L., Tamayo, P., Gaasenbeek, M., Sturla, L.M., Angelo, M., McLaughlin, M.E., Kim, J.Y., Goumnerova, L.C., Black, P.M., Lau, C., et al. 2002. Prediction of central nervous system embryonal tumour outcome based on gene expression. Nature 415: 436-442.

Qin, L., Wine-Lee, L., Ahn, K.J., and Crenshaw III, E.B. 2006. Genetic analyses demonstrate that bone morphogenetic protein signaling is required for embryonic cerebellar development. J. Neurosci. 26: 1896-1905.

Rios, I., Alvarez-Rodriguez, R., Marti, E., and Pons, S. 2004. Bmp2 antagonizes sonic hedgehog-mediated proliferation of cerebellar granule neurones through Smad5 signalling. Development 131: 3159-3168.

Romer, J.T., Kimura, H., Magdaleno, S., Sasai, K., Fuller, C., Baines, H., Connelly, M., Stewart, C.F., Gould, S., Rubin, L.L., et al. 2004. Suppression of the Shh pathway using a small molecule inhibitor eliminates medulloblastoma in $\mathrm{Ptcl}^{+/-} \mathrm{p}^{-/-}$mice. Cancer Cell 6: 229-240.

Rupp, C., Dolznig, H., Puri, C., Sommergruber, W., Kerjaschki, D., Rettig, W.J., and Garin-Chesa, P. 2006. Mouse endosialin, a C-type lectin-like cell surface receptor: Expression during embryonic development and induction in experimental cancer neoangiogenesis. Cancer Immun. 6: 10.

Sjostrom, S.K., Finn, G., Hahn, W.C., Rowitch, D.H., and Kenney, A.M. 2005. The Cdk1 complex plays a prime role in regulating $\mathrm{N}$-myc phosphorylation and turnover in neural precursors. Dev. Cell 9: 327-338.

Spiller, S.E., Ditzler, S.H., Pullar, B.J., and Olson, J.M. 2007. Response of preclinical medulloblastoma models to combination therapy with 13-cis retinoic acid and suberoylanilide hydroxamic acid (SAHA). I. Neurooncol. doi: 10.1007/ s11060-007-9505-1.

Taipale, J., Chen, J.K., Cooper, M.K., Wang, B., Mann, R.K., Milenkovic, L., Scott, M.P., and Beachy, P.A. 2000. Effects of oncogenic mutations in Smoothened and Patched can be reversed by cyclopamine. Nature 406: 1005-1009.

Thompson, M.C., Fuller, C., Hogg, T.L., Dalton, J., Finkelstein, D., Lau, C.C., Chintagumpala, M., Adesina, A., Ashley, D.M., Kellie, S.J., et al. 2006. Genomics identifies medulloblastoma subgroups that are enriched for specific genetic alterations. J. Clin. Oncol. 24: 1924-1931.

Wallace, V.A. 1999. Purkinje-cell-derived Sonic hedgehog regulates granule neuron precursor cell proliferation in the developing mouse cerebellum. Curr. Biol. 9: 445-448.

Wang, V.Y., Rose, M.F., and Zoghbi, H.Y. 2005. Math1 expression redefines the rhombic lip derivatives and reveals novel lineages within the brainstem and cerebellum. Neuron 48: 31-43.

Wechsler-Reya, R.J. and Scott, M.P. 1999. Control of neuronal precursor proliferation in the cerebellum by Sonic Hedgehog. Neuron 22: 103-114.

Wetmore, C., Eberhart, D.E., and Curran, T. 2000. The normal patched allele is expressed in medulloblastomas from mice with heterozygous germ-line mutation of patched. Cancer Res. 60: 2239-2246.

Wetmore, C., Eberhart, D.E., and Curran, T. 2001. Loss of p53 but not ARF accelerates medulloblastoma in mice heterozy- gous for patched. Cancer Res. 61: 513-516.

Zhao, H., Ayrault, O., Zindy, F., Kim, J.-H., and Roussel, M.F. 2008. Post-transcriptional down-regulation of Atoh1/Math1 by bone morphogenic proteins suppresses medulloblastoma development. Genes \& Dev. (this issue), doi: 10.1101/ gad.1636408.

Zurawel, R.H., Allen, C., Chiappa, S., Cato, W., Biegel, J., Cogen, P., de Sauvage, F., and Raffel, C. 2000. Analysis of $\mathrm{PTCH} / \mathrm{SMO} / \mathrm{SHH}$ pathway genes in medulloblastoma. Genes Chromosomes Cancer 27: 44-51. 


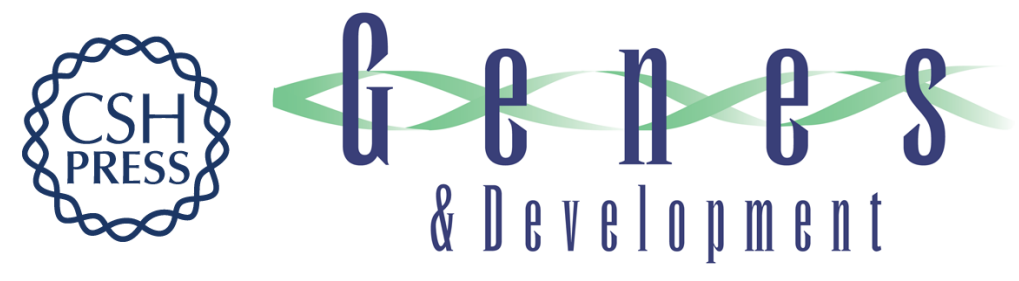

\section{BMPs oppose Math1 in cerebellar development and in medulloblastoma}

Matthew R. Grimmer and William A. Weiss

Genes Dev. 2008, 22:

Access the most recent version at doi:10.1101/gad.1657808

Related Content

References

License
Alerting
Service

Post-transcriptional down-regulation of Atoh1/Math1 by bone morphogenic proteins suppresses medulloblastoma development

Haotian Zhao, Olivier Ayrault, Frederique Zindy, et al.

Genes Dev. March , 2008 22: 722-727 Hh and BMP Converge on Atoh1

Annalisa VanHook

Sci. Signal. March , 2008 1: ec111

This article cites 50 articles, 24 of which can be accessed free at: http://genesdev.cshlp.org/content/22/6/693.full.html\#ref-list-1

Articles cited in:

http://genesdev.cshlp.org/content/22/6/693.full.html\#related-urls

Receive free email alerts when new articles cite this article - sign up in the box at the top right corner of the article or click here.

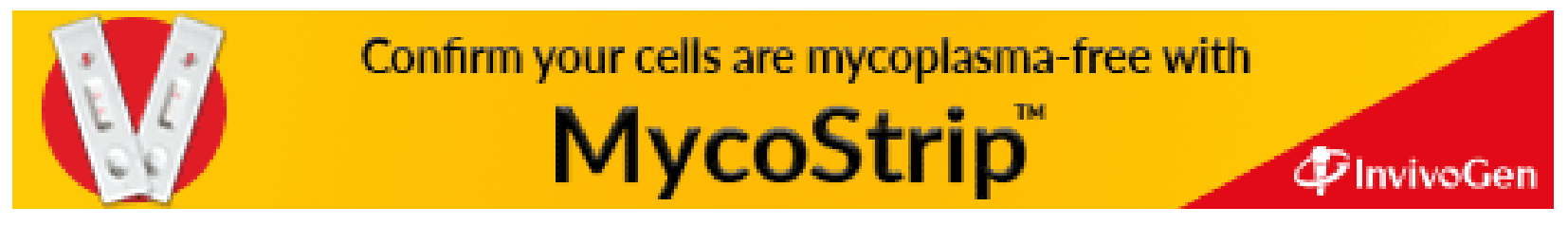

